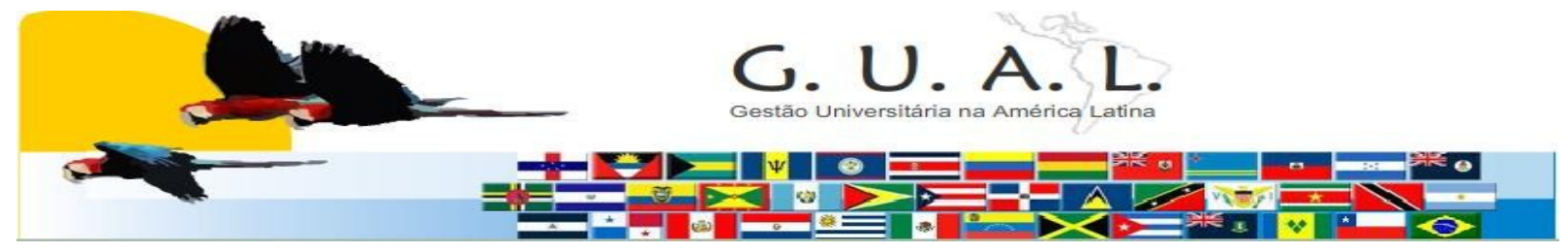

ISSN 1983-4535

\title{
IDENTIDAD DE LOS ABOGADOS Y FORMACIÓN UNIVERSITARIA EN UN MARCO DE CRISIS
}

Marcelo H. Efrón

\begin{abstract}
RESÚMEN
El presente trabajo, realizado en el marco del Seminario sobre Perspectivas FilosóficoPolíticas de la Educación Contemporánea a cargo del Prof. Dr. Carlos Cullen, tiene como objetivo efectuar una breve una aproximación a la idea de identidad de los abogados, para posteriormente abordar algunos enfoques sobre el derecho y justicia, haciendo un rápido pasaje hacia una muy simplificada referencia a la formación de abogados en el marco de lo que entendemos como una crisis de identidad profesional y, que se presenta temporalmente acompañando una revisión de la justicia como valor y como fin esencial del Estado.
\end{abstract}

Palabras clave: identidad, abogados, justicia, universidad.

\section{IDENTIDAD}

El término Identidad es impreciso y problemático; su uso frecuentemente resulta confuso, contradictorio y emotivamente cargado tanto en el lenguaje corriente como en el político.

Identidad deriva del latín idem, que significa "lo mismo" y de esta manera alude oposicionalmente a "lo diferente" o "lo otro".

En el ámbito académico, el término no presenta un panorama mucho más diáfano, su abordaje es necesariamente interdisciplinario.

El Diccionario Jurídico de Juan D. Ramírez Gronda define el termino como “... el conjunto de caracteres y circunstancias que constituyen la persona, esto es, lo que nos permite comprobar que un ser humano es igual a si mismo y distinto a todos los demás seres humanos..." lo cual describe con absoluta objetividad el fin que se persigue. 
El concepto Identidad, comienza a ser referenciado en las Ciencias Sociales aproximadamente en la década de los sesenta y de la mano del psicoanálisis (Lommitz), según se afirma en el Diccionario de Términos de la Sociología de la Cultura de Carlos Altamirano.

El abordaje de Pablo Vila, en el Diccionario de Ciencias Sociales de Torcuato Di Tella (2002), amplia el tema de las identidades, aquí culturales y sociales, hablando de a) el sujeto del iluminismo (sujeto soberano), b) el sujeto sociológico (sujeto formado en relación a "otros significativos" y c) el sujeto postmoderno (sujeto relacionado a "desestabilización", la diferencia, varias identidades).

Tony Becher plantea las identidades disciplinarias, hablando de las tribus académicas y su comportamiento y plantea una idea pluralista de la identidad. Rosanvallon habla de identidades fluidas, cambiantes, efímeras. Estos fenómenos refieren también, a una “declinación de lo social" que, impropiamente podría referirse a "la declinación de la política" lo que podría traducirse en el mundo occidental en la impotencia en los Estados, a la apatía de los ciudadanos, a la banalidad del gobierno político.

Desde la mirada que implica el enfoque jurídico, el concepto de identidad puede analizarse a partir de su propia inserción normativa. En este sentido, el derecho argentino como el de la generalidad de los países consagra un conjunto de principios denominados "derechos sobre la persona" que son los que garantizan el goce de nosotros mismos, asegurando al individuo el señorío de su persona, la actuación de las propias fuerzas físicas y espirituales.

Vélez Sarsfield, autor del Código Civil (1870), recoge estos principios y marca un rumbo indeleble en el derecho argentino, al sostener que los individuos no deben sus derechos a las constituciones u organizaciones políticas; es decir, el hombre es el objeto primero del derecho, es la causa, la que supone un ser humano libre, no un instrumento o medio de otro, sino un fin en sí mismo, que cuenta con individualidad, nombre y honor dentro de la sociedad.

Por ser la personalidad una cualidad jurídica que caracteriza la identidad y no un derecho subjetivo, no puede ser vulnerada por los demás sujetos, ni renunciada válidamente, ni ampliada ni disminuida convencionalmente. Tampoco pueden producirse estos efectos en razón de leyes extranjeras, las cuales serían en tales casos, inaplicables en el país como contrarias al orden público y al espíritu de nuestra legislación (art. 14 del Cod. Civil).

Ante la ley Argentina tanto la vida como la integridad física y el nombre, no constituyen derechos de la persona como si fuera algo separado de ella sino que son la 
persona misma, por dicha razón son derechos que no tienen en la ley modo de adquisición, modificación, transferencia, extinción.

Son derechos fundamentales del individuo, los originarios, que se adquieren por el sólo nacimiento y duran mientras dura la vida, otros derechos son absolutos e intransmisibles, son los relacionados a la vida, a la integridad, al nombre, a la propia identidad, a la igualdad, a la seguridad personal, a la privacidad. Todos ellos exigibles de respeto por los demás.

Planteados estos conceptos liminares que surgen a partir del análisis del instrumento legal, intentaremos identificar algunos enfoques particulares cuya enumeración no se agota pero que resultan conducentes en el ejercicio.

Juan Antonio Travieso (2002) reclama el derecho a la identidad planteando que la "singularidad de la biodiversidad humana plantea derechos a la diferencia. No se trata solo de respetar la alteridad que implica una simple tolerancia, sino que es lo que se denomina la “otredad”, es decir, la existencia de seres nacionales construidos por otras experiencias humanas. En el derecho internacional es posible efectuar una visión integral del derecho a la identidad entendiéndolo no separadamente sino articulado dentro del panorama de todos los derechos humanos..."

Cuando la Rigoberta Menchu (Premio Nobel), nos enfrenta al reconocimiento de los derechos indígenas, esta realidad aparece como la "otredad", lo diferente. Sin embargo, cuando las Abuelas de Plaza de Mayo reclaman la identidad de sus nietos, hablan de la "mismisidad", lo conocido, lo cercano.

Maria Cristina Reigadas (2000), en su trabajo Sociedad Global y Justicia sostiene que “... a partir de la necesidad de ir más allá de las denuncias del universalismo abstracto de los derechos humanos (o de su defensa irrestricta sin más) considero que la única vía de reconstrucción de lo politico en una sociedad global consiste en la construcción de una justicia global cosmopolita basada en derechos humanos interculturalmente ampliados, lo cual supone la articulación de diversas y complejas operaciones políticas, jurídicas, éticas y culturales..."

La misma autora afirma que “...si alguna enseñanza ha dejado el fracaso del actual orden (desorden) internacional para lograr un mundo más justo, es el de la ausencia de una cultura política que pueda elevarse por sobre los mas bajos umbrales de un etnocentrismo multifacético que socava la posibilidad de construir un mundo común mediante prácticas intersubjetivas".

Rev. GUAL., Florianópolis, v.2, n. 1, p.35-46, ano 2009. 
Indudablemente, construir una normatividad jurídica común, más allá de y a través de las diferencias culturales, implica un desafío inédito en la historia de la humanidad, ya que todo proceso de cambio supone el fantasma de la pérdida de identidad, tanto como el de la creación de identidades nuevas, sin que nada ni nadie garantice cuál será el resultado de los intercambios, trueques y aprendizajes, de las ganancias y de las pérdidas. Pero lo que sí tiene el carácter de una dolorosa certidumbre es que la humanidad no puede tolerar los márgenes de injusticia existentes y que el mundo está globalizado. Por ello, la creación de instituciones globales de justicia no constituye una opción, sino una necesidad. Y para ello, el etnocentrismo es el verdadero enemigo de la construcción de un mundo común.

La justicia global requiere procesos complejos que incluyen diversas dimensiones de lo social, practicas diferentes y que involucran decisiones, procedimientos y estrategias éticas, políticas y culturales para cambiar el sistema internacional actual basado en la anarquía del estado de naturaleza y dar lugar a un sistema diferente, en el cual los derechos universales amplíen los ya reconocidos hacia derechos interculturales y transculturales, mediante los cuales minorías y mayorías puedan ser protegidas, a partir del reconocimiento del principio de justicia.

Francisco Colom González (2000), del Instituto de Filosofía del Consejo Superior de Investigaciones Científicas de Madrid, España, al analizar en el El federalismo y la integración de la etnicidad, reconoce que “...toda unión federal tiene que dar respuesta a cuestiones tales como la división de los poderes legislativo y ejecutivo entre el gobierno central y los gobiernos periféricos, la representación de los ciudadanos en ambos niveles, la integración económica y jurídica del territorio en su conjunto y la participación de las subunidades estatales en los mecanismos de reforma constitucional. La presencia de minorías etnoterritoriales políticamente conscientes en un Estado federal añade a este panorama un elemento adicional de complejidad. El diseño de las estructuras federales con el propósito explícito de dar algún tipo de respuesta a la existencia de estas minorías supone un giro radical con respecto a los postulados federales clásicos de corte liberal. La identidad diferencial de estas últimas ha servido en ocasiones de plataforma reivindicativa para un reparto asimétrico de las competencias estatales entre las unidades que poseen una base etnonacional y aquellas regiones con una mera identidad administrativa, En última instancia, la aceptación o el rechazo de esta vía depende más de compromisos políticos concretos y de razones pragmáticas que de una consideración moral sobre los recursos políticos que 
supuestamente precisa el reconocimiento de las identidades diferenciales. Aun así, los modelos territoriales no pueden ser ajenos a consideraciones de carácter moral y político cuando se trate de optar entre la diversidad de estructuras federales posibles...".

Perfecto Andrés Ibáñez, (2001), integrante del Tribunal Supremo de España, en su trabajo sobre Ética de la Función de Juzgar, define características particulares que consagran la identidad de los Jueces. “... El Juez, en tanto que sujeto publico y con deberes de esa clase, está obligado a inspirar su práctica en un acervo de principios básicos universalmente compartidos, hoy constitucionalmente consagrados. Así, pues, tiene derecho a ser él mismo, pero, como jurisdicente, por imperativo legal, solo dentro de esos límites...".

Piero Calamdrei (1954) en su libro Elogio de los Jueces, destaca las características que realzan la identidad de Jueces y Abogados a través de un ejercicio de complementación. En esta obra clásica, el maestro italiano advierte de "ciertas semejanzas y de ciertas diferencias entre jueces y abogados", señalando que "advocati nascuntur, iudices fiunt" (los abogados nacen, los jueces se hacen); no ya en el sentido de que se pueda ser un buen abogado sin la preparación adecuada, sino en el de que aquellas virtudes de combatividad y de impetuosidad que más se aprecian en la abogacía, son propias de la juventud apasionada y desbordante, mientras que solo con el correr de los años maduran las cualidades de ponderación y de cordura que constituyen las mejores cualidades del juez. El juez es un abogado moderado y purificado por la edad; a quien los años le han quitado las ilusiones, las exageraciones, las deformaciones, el énfasis, y acaso también la impulsiva generosidad de la juventud; el juez es lo que queda después de suprimidas del abogado todas aquellas virtudes exteriores por las cuales el vulgo las admira. El autor resume que "...El abogado es la bullidora y generosa juventud del Juez. El Juez es la ancianidad reposada y ascética del Abogado...”.

Al identificar quien es abogado, Ángel Osorio (1934), insigne catedrático español que fuera Decano del Colegio de Abogados de Madrid en su libro El alma de la toga, remarca que en éste, “... la rectitud de la conciencia es mil veces mas importante que el tesoro de los conocimientos. ...El abogado primero debe ser bueno; luego, ser firme, después, ser prudente; la ilustración viene en cuarto lugar; la pericia en el último... Abogado es en conclusión, el que ejerce permanentemente la Abogacía. Los demás serán Licenciados en Derecho, muy estimables, muy respetables, muy considerables, pero Licenciados en Derecho nada mas....".

Rev. GUAL., Florianópolis, v.2, n. 1, p.35-46, ano 2009. 
Como conjugamos estas "viejas ideas" sobre la identidad, con las nuevas, modernas y utilitarias definiciones sobre el rol de los abogados en una sociedad de la que forman parte, que se encuentra en crisis, formados en instituciones que se encuentran en crisis, absorbiendo teorías y conocimientos que están en crisis y para participar en un sistema jurídico que también esta en crisis....

\section{DERECHO Y JUSTICIA}

Al definir conceptos acerca de la identidad en términos generales, con la intención de acercarnos a la identidad y características particulares de los abogados, no cabe duda que debemos enfocar, aunque tangencialmente, una aproximación al término Justicia.-

Que el Derecho no es la Justicia, parecería obvio señalarlo, pues se dan de hecho sistemas jurídicos injustos... Sin embargo, el Derecho tiene mucho que ver con la Justicia, como que ".. todo derecho aspira a ser justo: tiende a la Justicia..."

En este marco, las concepciones son variadas y en general altamente divergentes.

Los criterios clásicos que describen a la Justicia como una "armonía", como una igualdad proporcional, como una medida armónica, de cambio y de distribución (Stammler), conforme a lo cual ordenamos la materia jurídica que conduce a la idea de comunidad pura, de hombres libres, a partir de "una sola idea de justicia” con valor absoluto, lo que genera “ideales jurídicos diversos”, y cada uno de ellos será justo..

Partiendo de la naturaleza humana, se llega a la conclusión de que la justicia exige que "todo sujeto sea reconocido por aquello que vale" y que a cada uno le sea atribuido "aquello que le corresponde" (Del Vecchio), siguiendo aquella formula de Ulpiano "Jus seum cuique tribuere", es decir, dar a cada uno lo que le corresponde, o lo suyo.....

En definitiva, estos aspectos han sido tenidos presentes para determinar "proporcionalidad" en los términos de la relación jurídica, esto es, se trata de saber cual es el criterio para establecer la igualdad, cual será la medida que habremos de utilizar para calibrar esa igualdad, lo cual nos conduce al tema de la estimación jurídica y a los criterios de valoración jurídica (Cossio).-

Hans Kelsen (1934) a partir de la elaboración de su "Teoría Pura del Derecho" critica a los juristas que anteponen la idea de justicia como conformadora del derecho, ya que sostiene, ésta no es mas que la imposición de un interés sobre otro, o un consenso entre intereses individuales, por lo que a la postre, “...la justicia no es más que una ilusión...” 
Para Kelsen no es posible saber lo que es la justicia, y en todo caso, el criterio medianamente valido de lo "justo" se acercaría a lo "valido jurídicamente"... Por lo que la conclusión a que arriba es que ninguna ley puede ser injusta, en la medida que cualquier norma jurídica no podría considerarse aisladamente, sino como parte integrante de un marco normativo complejo y unitario, que debe lógicamente contener sus propios mecanismos de producción y derogación, dando lugar a un "orden jerárquico" de normas, en ultima instancia, un orden "coherente".

Se admite en este esquema, que la validez de las normas derivan del modo de producción de las mismas y no de su contenido, por lo que se admitiría la existencia de leyes de contenido arbitrario, siempre que se reconozca su legalidad (procedimiento) que podría no coincidir con su justicia (legitimidad).

La Justicia como imparcialidad (Rawls) destaca con una de sus primeras reflexiones acerca del papel de la justicia: "La justicia es la primera virtud de las instituciones sociales, como la verdad lo es de los sistemas de pensamiento" ... “.. no importa que las leyes e instituciones estén ordenadas y sean eficientes: si son injustas han de ser reformadas y abolidas...." posición ésta altamente compleja en la medida que las normas como tales siguen existiendo en el mundo jurídico, independientemente de su valoración, y siempre y cuando se entienda que legalidad, presunción de legitimidad y ejecutoriedad configuran principios del derecho positivo cuyos efectos jurídicos impactan directamente en sus destinatarios de hecho y de derecho.-(Hutchinson).-

Rawls sostiene que “.. aquellos que sostienen diferentes concepciones de la justicia pueden entonces estar de acuerdo en que las instituciones son justas cuando no se hacen distinciones arbitrarias entre las personas al asignarles derechos y deberes básicos y cuando las reglas determinan un equilibrio debido entre pretensiones competitivas a las ventajas de la vida social..... aunque no es el único requisito para una comunidad humana viable. Hay otros problemas fundamentales, en particular los de coordinación, eficacia y estabilidad..”

Rawls considera que los principios de justicia que son objeto de un acuerdo entre personas racionales, libres e iguales en una situación contractual justa, pueden contar con una validez universal e incondicional. Su teoría justicia como imparcialidad, apoyado en la idea de que solamente a partir de condiciones imparciales se pueden obtener resultados imparciales. La imparcialidad de la situación contractual a la cual él llama posición original se garantiza por un velo de ignorancia que impide a los participantes del acuerdo observar y tener todos 
los conocimientos particulares, entre ellos los relacionados con su propia identidad y con la sociedad a la cual pertenecen. De este modo, se depura el acuerdo de la influencia de factores naturales y sociales que se consideran contingentes desde el punto de vista de la justicia, y a la vez se asegura el tratamiento equitativo de las distintas concepciones del bien.

Es importante analizar en el trabajo de Rawls que gran parte de la coherencia teórica de su desarrollo tiende a demostrar la validez de su concepción acerca de la justicia frente al utilitarismo. El principio de utilidad termina por identificar las nociones de lo bueno y de lo justo, al ver como justa la distribución de beneficios que maximice el bien, el cual el utilitarismo clásico asocia con la satisfacción del deseo. Así como un hombre, para realizar su propio bien, hace siempre un balance de pérdidas y ganancias de modo que en un momento pueda resultarle racional imponerse un sacrificio para obtener ganancias en el futuro, de la misma manera sería racional para una sociedad maximizar su bien, aún cuando en aras de lograr el mayor balance neto de satisfacción posible imponga sacrificios a una parte de sus miembros. Al hacer extensivo a la sociedad el principio utilitarista de elección individual, este principio se vuelve indiferente al modo de distribución de la suma de satisfacciones entre los individuos, lo que terminaría por justificar instituciones como la esclavitud, si los sacrificios de unos cuantos se vieran compensados ampliamente por la satisfacción de otros en el balance total.

En este sentido, no hay, en principio, razón por la cual las mayores ganancias de algunos no han de compensar las menores pérdidas de otros, o lo que es más importante, por qué la violación de las libertades de unos pocos no pudiera ser considerada correcta por un mayor bien compartido por muchos.

Frente a este esquema de crítica al utilitarismo clásico, Rawls promueve su teoría de la justicia que “... represente una alternativa al pensamiento utilitario en general y por lo tanto a sus diferentes versiones..."

Así, la formulación de su teoría adopta un procedimiento de naturaleza contractualista en el cual una serie de individuos sobre los cuales ha caído un grueso "velo de ignorancia" los sitúa en una "posición original" donde nadie sabe quién es, y lo único que conservan además de la capacidad de razonar, son las nociones económicas (bienes escasos) y sociológicas (clases sociales) más elementales.

Así, mediante un "contrato social hipotético", establecerán la estructura básica de la sociedad en que vivirán y por medio de este hipotético contrato se establecerán los principios 
de justicia que regirán la vida social, a través de un método que es justo por sí mismo, esto es la justicia como imparcialidad.

Rawls sostiene que "una concepción de justicia es más razonable que otra, si personas racionales en la situación inicial escogen sus principios por encima de los otros por el papel mismo de justicia..." a partir de:

1) Principio de libertades, es decir, distribución de igual número de esquemas de libertades para todos.

2) Principio de diferencia donde “...las desigualdades económicas y sociales han de estar estructuradas de manera tal que aseguren: a) mayor beneficio de los menos aventajados, y b) que cargos y posiciones estén abiertos a todos en condiciones de justa igualdad de oportunidades..."

En resumen, las circunstancias de la justicia pueden describirse como las condiciones normales en las cuales la cooperación humana es tanto posible como necesaria; es decir, existe un conjunto de condiciones subyacentes que dan origen a la necesidad de escoger entre las posibles configuraciones sociales y suscribir un acuerdo acerca de las porciones distributivas correctas (según Rawls, a través de los dos principios). Estas condiciones son las circunstancias de la justicia, y pueden agruparse en aquellas objetivas y subjetivas.

\section{IDENTIDAD DE LOS ABOGADOS Y FORMACIÓN UNIVERSITARIA EN UN MARCO DE CRISIS}

En general, los Planes de Estudio de las Carreras de Abogacía que se dictan en Universidades Públicas, están cimentados en ciertos elementos constitutivos básicos, sin perjuicio de la impronta institucional que cada una de ellas articula en el modelo, atendiendo a cuestiones Institucionales, organizacionales, culturales, sociales, económicas, regionales que orientan los perfiles de la carrera, pero que en el momento de formular la estructura del diseño, no pueden apartarse de ciertas características que son comunes y tradicionales, y que hacen a la formación de los alumnos y al perfil del egresado.

Por una parte, la formación en el pensamiento jurídico, su método y su aplicación, a partir de una actitud crítica e innovadora. Ello supone un amplio conocimiento de las normas jurídicas adecuado al desarrollo de habilidades que permitan enfrentar los problemas profesionales de forma integral.

Rev. GUAL., Florianópolis, v.2, n. 1, p.35-46, ano 2009. 
Capacidad para interpretar las normas, la doctrina jurídica y la formación para la creación de nuevas normas, así como conocimiento y habilidad para resolver problemas concretos de orden jurídico.

Desarrollo de aptitudes reflexivas y de adaptación para adecuarse a las nuevas demandas que los cambios económicos, políticos, sociales y culturales imponen a la profesión, sin perjuicio de la habilidad, conocimiento e interés para emprender proyectos y trabajos de investigación jurídica como forma de articular el crecimiento académico y profesional.

De acuerdo a las características intrínsecas de la profesión, las instituciones universitarias impulsan una "formación integral" dirigida al desarrollo de un perfil profesional de tipo "generalista".

Ello significa, como ocurre en otros niveles de escolaridad previos, que el estudiante recibe una formación de base o básica que lo inserta en el medio científico o disciplinar, para luego avanzar en los espacios curriculares de formación sustantiva y procedimental, que lógicamente, también serán de base o básicos para culminar sus estudios con alguna practica.

Pocos de estos planes, aun en el caso de los más modernos, han variado esta concepción del derecho luego de casi 100 años, entendiendo que luego de su egreso, el abogado podrá elegir continuar con su formación más específica en áreas acordes a su interés, lo cual ya de por si representa una actividad voluntaria del graduado y casi en su absoluta mayoría, onerosa y por lo tanto, en muchos casos, inaccesible.

Las Facultades de Derecho tienen como objetivo principal, la formación profesional de los abogados. Se dejará de esta forma de lado otros objetivos que resultan imprescindibles en otras disciplinas, como la promoción y el desarrollo de la investigación.

La formación de los abogados, en el sentido más amplio, constituye un requisito indispensable para el ejercicio de las diversas funciones jurídicas, en la forma en que esta se manifiesta. Sin embargo, no todos los graduados se dedican al ejercicio de la abogacía en la forma tradicional, o estricta, es decir, como abogados litigantes cuyo principal objetivo es la defensa de intereses en juicio.

Se encuentran cada vez mas, abogados que se dedican al asesoramiento o consultoría en el ámbito de la Administración Pública o de instituciones privadas; la magistratura, el ministerio público, la docencia terciaria y universitaria, inclusive la representación política, actividades estas que requieren formación especifica y que no son consideradas cuando se 
establecen las exigencias o requisitos a evaluar en el proceso de transmisión y aprendizaje de habilidades, practicas y conocimientos.

Y no cabe duda que estas actividades se desarrollan en un marco de crisis donde el predominio de la globalización y la internacionalización de la educación, constituyen un símbolo característico del siglo XXI y representan sin duda, una variable de considerable influencia en la formulación por parte del Estado, de políticas públicas que consideren el valor estratégico de la Universidad.

Estos cambios, la rapidez con que se producen, sus efectos sociales, económicos y culturales, entre otros requieren reformular la necesaria articulación del sistema educativo y naturalmente, la relación entre las instituciones universitarias y el propio Estado (Pérez Lindo).

La crisis de autoridad que vive nuestra sociedad y la constante lucha entre el ser y el deber ser de las organizaciones educativas como instituciones de derecho publico producen un impacto de tal magnitud que nos obliga a replantear el rol político, social, cultural y educativo que poseen y sin lugar a dudas, reevaluar el lugar que se les asigna en un estado de derecho, partiendo de la premisa de su integración a una organización administrativa nacional.

$\mathrm{Y}$ es sin duda en este contexto en que se produce la contradicción más importante entre el interés, la vocación y la identidad del estudiante de derecho, la valoración institucional del derecho y la justicia, su formación técnica y profesionalista y el contraste con la realidad.

En definitiva, resulta imposible conjugar la identidad del abogado con un criterio de justicia, sea ésta una medida armónica; una proporcionalidad; una validez legal o una formula contractual de imparcialidad, entre alguna de ellas.-

Sin embargo, la etapa de formación del estudiante y futuro graduado enfrenta grandes contradicciones entre los anquilosados contenidos de su formación de preponderante corte profesionalista y la realidad del sistema y de la sociedad en que deberá ejercer su labor.-

No se trata únicamente de competencias. Tampoco de formación generalista.- De lo que se trata es de entender como señala Cullen (2004), que "el deber es en realidad, respeto hacia los otros, y que la obligación moral es en realidad, exigencia de justicia..."

A decir de Osorio; “.. lo que al abogado importa no es saber el derecho, sino conocer la vida. El derecho positivo esta en los libros...la justicia no es fruto del estudio sino de una 
sensación...” Por estas razones, “. .la abogacía no se cimenta en la lucidez del ingenio, sino en la rectitud de la conciencia..."

Seguramente será parte del desafió, congeniar estos aspectos a veces tan disímiles para nuestros hombres y mujeres y para nuestra sociedad.-

\section{BIBLIOGRAFÍA}

De Ipola, Emilio (2001), "Ser y no ser. Un concepto en crisis" en Encrucijadas, UBA, Buenos Aires.

Di Tella, Torcuato (2001), Diccionario de Ciencias Sociales y Políticas, EMECE, Buenos Aires.

Efron, Marcelo Héctor - Nicodeme, Leticia (2007) "La Formación de Abogados y la demanda en la Administración Publica Nacional" - VII Coloquio Internacional sobre Gestión Universitaria en América del Sur - Universidad Nacional de Mar del Plata.

Garretón, Manuel (1996), Crisis de la idea de Sociedad?, en Revista de Sociología, N 10, Fac. Cs. Sociales, Universidad de Chile.

Garreton, Manuel Antonio, (1999), "Las Sociedades latinoamericanas y las perspectivas de un espacio cultural, Una introducción al debate”, en Garreton, Manuel Antonio (coord.), 1999, AMERICA LATINA: UN ESPACIO CULTURAL EN EL MUNDO GLOBALIZADO, Debates y Perspectivas, Convenio Andres Bello, Santafe de Bogota.

Travieso, José Antonio (2001), "El derecho a la identidad. Un enfoque jurídico" en Encrucijadas. UBA. Buenos Aires.

Cullen, Carlos (2004) "Autonomía moral, participación democrática y cuidado del otro" Novedades Educativas - 3ra edic. Buenos Aires.

Osorio, Angel (1934) "El alma de la toga" - Librería El Foro SA - Edición de Junio de 1997. 